\title{
HISTORIA DEL CORAJE HACIA LA BIOGRAFÍA DE RICARDO GARIBAY
}

Luis Enrique Escamilla Frías *

\section{RESUMEN}

La biografía de Ricardo Garibay (Tulancingo, 923 Cuernavaca, 999) puede dividirse tanto temática como cronológicamente. Temáticamente, en tres aspectos: vida y obra intelectual; su vida de hombre público, y su existencia privada. Cronológicamente, también en tres etapas: una etapa desde que nace hasta que cumple 7 años y decide ser escritor; otra es su juventud en la Ciudad de México, donde recibe instrucción universitaria, consigue sus primeros empleos, forma una familia y publica en medios periódicos; y finalmente, a partir de 954, año de publicación de Mazamitla, su primera novela, cuando dice por fin sentirse dueño de algunas líneas y se convierte en el escritor cuyo carácter explosivo hizo fama. Tal mi hipótesis que pretende sentar la base para su biografía.

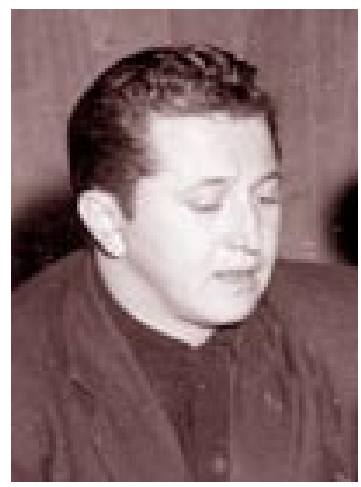


* Estudiante de Letras Hispánicas, UNAM, e Historia de México, UAEH, y periodista en Milenio. E mail: luis.enrique.frias@gmail.com.

\section{ABSTRACT}

The Biography of Ricardo Garibay (Tulancingo, 1923 Cuernavaca, 1999) can be divided either thematically or chronologically. Thematically in three aspects: his intellectual and life work; his public life; and his private life.

Chronologically, also three stages: the first stage of his life from birth to 17 years old when he decided to dedicate his life to writing; the second stage as a young man in Mexico City where he attended University, obtained his first jobs, formed a family and was first published; and finally his life after 1954, the year his first novel Mazamitla was published and finally felt owner of lines that he had written which converted him into a author famous for his explosive character.

This is the hypothesis that I intend to lay as the base for his Biography

\section{INTRODUCCIÓN.}

\section{DELIMITACIÓN METODOLÓGICA}

Sin ninguna restricción, una Biografía de Ricardo Garibay pudiera resultar un tema bastante interesante, pero también requeriría agotar todas 0 , al menos, una gran parte de las fuentes directas e indirectas, que han hablado del autor, incluyendo panfletos y demás publicaciones menores cuya ubicación en archivos distantes y/o difíciles, pueden estar fuera del alcance. De ahí que este tema tenga una acotación de orden práctica y metodológica. 
Al investigar sobre Ricardo Garibay, es posible advertir que su universo biográfico oscila alrededor de tres asuntos capitales: ) su apasionada y furibunda vida personal, en todo momento acompañada de, 2) los altibajos que atravesó a causa de su vida pública y de su relación con los círculos del poder presidencial; todo lo cual contribuyó y fue materia prima para, 3) su prolífica obra intelectual, la cual en gran parte abreva de sus experiencias personales. En otras palabras, estudiar la biografía de Ricardo Garibay en términos de su vida personal, sus relaciones públicas y su obra intelectual, equivale a delimitar el tema de estudio biográfico de manera que, lejos de reducirlo innoblemente, se concentren en tres quintaesencias todos los contenidos de información que, estudiados de otro modo sería imposible abarcar debido a diferentes complicaciones.

Conviene dejar establecido que Ricardo Garibay es un personaje fuera de serie, cuyo mero carácter concita a indagar más sobre su existencia. Tuvo fama de que públicamente se trataba de alguien explosivo, provocador e intransigente ante cualquier asunto político o literario; pero en lo privado era dócil, enamoradizo, libidinoso, religiosamente enfermizo, en fin, contradictorio. Tanto los que tuvieron amistad con él, como sus adversarios, no han podido por menos de reconocer que se trata de todo un personaje.

Garibay nace en Tulancingo, Hidalgo, el 8 de enero de 923. Las raí- ces de su madre, Bárbara Ortega, estaban en el municipio hidalguense de Metztitlán; su padre, Ricardo Garibay, proveniente de la Ciudad de México, tenía por oficio la agricultura, el cual apenas si daba los recursos necesarios para mantener a la familia. Después de vivir un tiempo en Tulancingo, la familia se marcha a la capital del país, a la vecindad en donde Garibay verá transcurrir los primeros años de su vida. Años mozos que están cubiertos de penurias materiales y de una religión asfixiante impuesta por su madre; hechos que quedarán establecidos en Fiera infancia $y$ otros años, su novela de memorias de 982 . 
En la capital del país creció y se hizo inspector de burdeles de lujo, jefe de prensa de la Secretaría de Educación Pública, profesor de literatura y escritor de decenas de cuentos, una veintena de crónicas largas sobre la vida en México, más de 40 novelas, numerosos guiones cinematográficos $y$ varios centenares de columnas en el diario Excélsior bajo la égida de Julio Scherer García. Sin duda, un autor muy prolífico. En una entrevista recuerda cuando, ya consagrado, un dignatario de Tulancingo lo invitó a develar la plaquita de una avenida con su nombre. Viajó de Cuernavaca, donde vivía, para llevarse tamaño coraje. "Era una callecita de terracería, más cochambrosa que las de mi niñez. Dije: así no." Por fin, muere en 999 sin haber alcanzado su largamente acariciada gloria editorial, la cual, sin embargo, llegaría dos años después, en 200 , con la edición de los diez tomos de lujo de sus Obras Reunidas. A propósito de esta gloria inalcanzada, un amigo de Garibay admitió: "Me dijo que a él no le importaban los reconocimientos excepto el premio Nóbel. Pero se reía inmediatamente. Él decía que había una especie de mafia en la entrega de premios de la literatura mexicana que controlaban cuatro o cinco escritores. Que ellos decidían quién ganaba, y que, por su puesto, lo tenían excluido. Aunque le dieron varios premios en el interior del país, realmente él despreciaba muchos de los premios convencionales que había. Decía que estaban planeados, que era más política que reconocimiento a la calidad literaria."

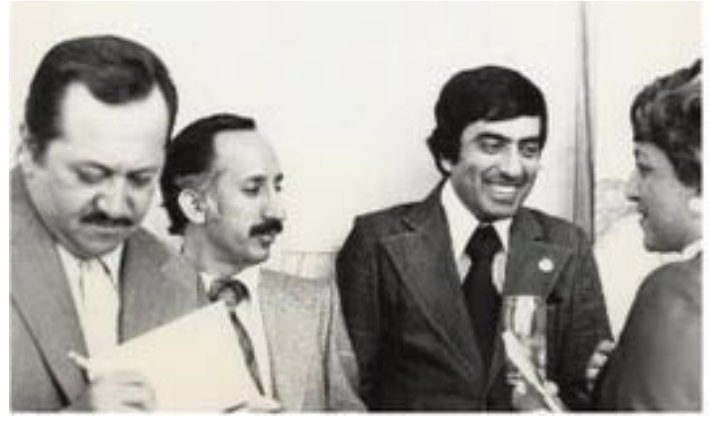

Garibay y Gustavo Sainz

En lo familiar, contrajo matrimonio con Minerva Velasco, y tuvo 
cinco hijos: Mónica, Minerva, Ricardo, María y Juan Matías. La primera fase de hombre público tuvo inicio con sus primeros empleos en el sector gubernamental federal, así como en su colaboración con opiniones políticas en los mencionados periódicos, y trabó amistad con los círculos del poder presidencial, empezando por el presidente Gustavo Díaz Ordaz y su sucesor, Luis Echeverría Álvarez. Con éste sí tuvo una amistad más cercana y verdadera; amistad que, sin embargo, acabaría pronto en desavenencias mutuas. "Echeverría se enojó conmigo y me mandó a morirme de hambre. $Y$ lo consiguió", consignaría Garibay (Garibay,200 : 365). Por ello no es extraño que todo cuanto escribió sobre los grupos de poder y literarios del país esté cargado de animadversión y aun de rencor.

Pero a inicios de los años 90 le detectaron un cáncer de próstata que se extendió hasta alcanzar la región de la espalda ${ }^{2}$. La enfermedad no lo abandonaría; antes bien, iba a recrudecerse hasta que en las postrimerías de esa misma década sus apariciones públicas se redujeron a cero, muriendo el 3 de mayo de 999, víctima de la enfermedad.

Lo grave es que personaje de tamaña trayectoria no ha sido estudiado desde el punto de vista de la Historia. Como no sean trabajos periodísticos, o ensayos que recientemente le han dedicado amigos suyos, o investigaciones de estética literaria que se realizan en las aulas de las Facultades de Letras ${ }^{3}$, no existe investigación histórica que integre las tres facetas más notables de Ricardo Garibay. Hecho que permite abrevar en una amplia veta, por partida doble. Por un lado, el personaje y su legado literario son imprescindibles en la literatura mexicana $y$, por otro, su vida no ha sido reseñada significativamente desde la perspectlva histórica 0 , más precisamente, biográfica. 


\section{SIN BIOGRAFÍAS ANTERIORES}

Una vez que ha sido enmarcado el ámbito de estudio de la biografía de Garibay, hay que decir en hasta qué punto se ha investigado actualmente el tema. Es decir, su biografía desde los tres puntos de vista sugeridos: la interrelación entre su vida privada con sus relaciones públicas y su trabajo intelectual y artístico. Pues bien, hasta el momento, no existe ningún esfuerzo de investigación histórica al respecto.

En todo caso, las investigaciones precedentes que se pueden encontrar a propósito de Garibay se reducen a material de escasa extensión, periodístico y/o de análisis literario. En un breve listado del referido material bibliográfico se advierte enseguida que se trata de información subjetiva, cuando no parcial. Véase:

- La conquista de la palabra, entrevista con Ricardo Garibay. Autoras: Socorro Arce y Rocío Aceves. Colección Voz de Tinta. Ed. Universidad de Colima, México, 999. 7 páginas. En un esfuerzo de la Universidad de Colima, su Coordinación de Extensión Cultural publica una serie de libros-entrevistas con varios escritores mexicanos relevantes. Además de los tomos de Ethel Krauze, Guillermo Schmidhuber de la Mora y Emilio Carballido, entre otros, la colección editorial "Voz de Tinta" publica la entrevista de largas horas que Garibay sostuvo con las autoras. El autor charla una por una sobre 22 de sus obras.

- Signos vitales de Ricardo Garibay. Autora: Iris Limón. Editorial Colibrí. México, 2000. 208 páginas. Pensado originalmente como una biografía, el libro terminó siendo un retrato a muchas voces. El volumen está armado a partir de entrevistas con el propio Garibay y personas allegadas a él, tales como Fausto Vega, Rubén Bonifaz Nuño, Vicente Leñero, José María Fernández Unsaín, María Luisa Mendoza, Javier Sicilia y una de las hijas del escritor, María Garibay, entre otros. 
- Escribir para seguir viviendo: entrevistas con Ricardo Garibay. Auto- res: el propio Ricardo Garibay y Ricardo Venegas. Ed. Instituto de Cultura de Morelos. Cuernavaca, 2000. 72 páginas. En la preparatoria y en la Facultad de Letras, Garibay tuvo por compañera a Juana Khun, la que más tarde iba a dar a luz a Ricardo Venegas. Años después, Garibay se iría a vivir a Cuernavaca, donde también radicaba Venegas. En el libro, después de narrar cómo se hicieron amigos, Venegas da pie a una serie de entrevistas hechas entre 997 y 2000. Se trata de entrevistas narra- das con Garibay.

- Señor mío y Dios mío. Ricardo Garibay: la fiera inteligente. Autora: Alejandra Atala. Editorial Océano, México, 2003. 260 páginas. Alejandra Atala tuvo una relación estrecha con Ricardo Garibay. Por haberse casado con Juan Matías Garibay, pasó a ser nuera del novelista: condición que pronto se transformó en la de discípula, al trabajar junto con él. Con la seguridad de que su cercanía al maestro merecía darse a conocer, cuatro años después del fallecimiento de Garibay, Atala detalla cómo era la convivencia con él. Es un trabajo a medio camino entre el libro de memorias y la novela autobiográfica, cuyo eje en todo caso, es la figura preponderante de Ricardo Garibay.

- Diálogos hidalguenses. Autores: Ricardo Garibay y Luis Corrales Vivar. Ed. Universidad Científica Latinoamericana de Hidalgo. Carece de lugar y año de edición. 208 páginas. Siendo Luis Corrales Vivar conductor de un programa de televisión local en Pachuca, Hidalgo, se dio a la tarea de hacer una serie de entrevistas con Ricardo Garibay. En cada una hablaban de tópicos específicos, por ejemplo: la soberbia, el amor, el odio, el sionismo y otros; los programas se grabaron y transcribieron para darle forma de libro a este trabajo.

- Memoria, espíritu y astucia en la obra de Ricardo Garibay. Autor: Ri- cardo Venegas. Inédito. Venegas escribió este libro de 
ensayo gracias a una beca del Centro Mexicano de Escritores en el periodo 2003-2004. En él se centra en los aspectos literarios de la obra de Garibay, los entremezcla con apreciaciones subjetivas sobre su biografía, y todo lo condimenta con detalles intimistas producto de la relación amistosa entre ambos.

Son todos los libros que se pueden encontrar cuyo único tema sea o la obra de Garibay, o su vida, o bien la relación entre ambas con un aderezo personal de los respectivos autores. Por supuesto, existe una gran cantidad de fuentes secundarias en las que se hace referencia a Garibay: artículos en revistas literarias especializadas, inclusiones en antologías, ensayos biográficos, menciones de él en libros de historia de la literatura mexicana, artículos en periódicos y revistas de circula- ción general. Pero son de naturaleza mucho más general que la serie de libros antedichos. Es ocioso traer a cuento toda esta hemerografía y bibliografía periférica, porque si los libros mencionados son, históricamente hablando, los más serios y amplios que existen en torno a la obra de Garibay, las publicaciones menores se descartan de antemano. Se puede hablar, sin embargo, de las publicaciones periódicas que en alguna ocasión dedicaron sus portadas o sus contenidos enteros al estudio de nuestro personaje. Helas aquí:

- La Jornada Semanal. Suplemento cultural del diario La Jornada. Núm.243. 6 de febrero de 994. En la portada del suplemento está una fotografía de Ricardo Garibay, y se ofrece una entrevista con él. En 5 páginas interiores Garibay habla escuetamente de su vida y de algunas anécdotas. Lo más importante es que una vez más, habla mal de los premios literarios, y se jacta de haber rechazado tanto una beca que le fue otorgada por el Sistema Nacional de Creadores -estímulo que dijo no haber solicitado- como una invitación a formar parte de la Academia Mexicana de la Lengua. 
- Tierra Adentro. Revista pública de aparición bimestral. Número 34, Noviembre-diciembre de 995. El órgano de difusión, dependiente del Consejo Nacional para la Cultura y las Artes, destaca en su portada la inclusión de Garibay. En efecto, se incluye una serie de cuentos cortos titulados Morir de amor, los que más tarde se incluirían erróneamente en las Obras reunidas con fecha de $996^{4}$; más sendas entrevistas en las que por un lado Garibay habla sobre su oficio de escritor y sobre algunas teorías de literatura en general.

- Hidalgo a vuelo de pájaro. Visión del estado desde la zona Tepeji-Tula. Revista Núm. 8. Tomo . Año , 25 de febrero de 2004. Desde su porta- da advierte lo que hay adentro. "Homenaje al escritor Ricardo Garibay ( 923- 999)". En efecto, al interior se incluyen textos de Eugenio Aguirre, Rubén Bonifaz Nuño, Josefina Estrada, Miguel Ángel Granados Chapa, Iris Limón, María Luisa Mendoza, Miguel Ángel Muñoz, Javier Sicilia, Ignacio Trejo Fuentes, Arturo Trejo Villafuerte y José Antonio Zambra- no; naturalmente, todos hablan en términos apologéticos de Garibay. Además, la revista tiene incluidos fragmentos de novelas y cuentos del propio Garibay.

- La Jornada Semanal. Suplemento cultural del diario La Jornada. Núm.542. 24 de julio de 2005. El suplemento cultural abre con una portada donde aparece una ilustración con la imagen de Garibay, hecha por la artista plástica Maries Mendiola. Adentro se incluye un ensayo del mencionado Ricardo Venegas y otro del antropólogo y amigo de Garibay, Santiago Genovés. Finalmente, hay una entrevista que le hiciera Alberto Vadas. Garibay habla ahí de su obra, de su vida, de su experiencia en la industria fílmica de México.

En suma, se advierte que el periodismo cultural generado a propósito de Garibay es predominantemente de signo 
apologético. Si bien, es ver- dad que esta muestra de publicaciones periódicas no es ni la única ni acaso la más exhaustiva en todo medio cultural mexicano, también hay que dejar manifiesto que se trata de los únicos medios de información que a nivel nacional y estatal han dedicado ex profeso portadas y páginas completas al estudio de algún aspecto de Ricardo Garibay. En todos es francamente visible la tonalidad de celebración hacia el escritor, con la evidente exclusión de crítica alguna. En todo caso, por esta vía camina la hemerografía que existe en torno a Garibay.

\section{RICARDO GARIBAY: VIDA, RELACIONES E INTELECTUALIDAD (1923-1999)}

Una vez comprobado que las investigaciones precedentes sobre Ricardo Garibay no pasan de ser periodísticas, o bien de teoría literaria aplicada al estudio de algunas obras suyas, es posible plantear nuestra hipótesis.

Como ha quedado dicho, alguna biografía de Garibay es algo inasequible hasta el día de hoy. El único intento, de Iris Limón, se quedó en el camino porque el propio Garibay se negó a aceptarlo. Según revela la propia Limón, su libro de entrevistas Signos vitales de Ricardo Garibay originalmente estaba llamado a ser una biografía, pero Garibay se negó a tal empresa, pensando en el grande daño que podía hacerle a su familia cuando ésta descubriera las infidencias y demás desvíos de los que fue protagonista. Por toda biografía, al final Garibay únicamente aceptó que se le hicieran largas entrevistas; mismas que Limón adicionó con otras hechas al poeta Rubén Bonifaz Nuño, a los escritores Vicente Leñero y María Luisa "La China" Mendoza, entre otros amigos del narrador. 
Y a casi nueve años de su muerte (acaecida el 3 de mayo de 999), no se ha escrito el texto biográfico de este personaje. Este trabajo se fundamenta en que la vida de Ricardo Garibay giró en todo momento en torno a los ejes mencionados: a saber, su obra, su vida privada y sus relaciones públicas: y la inseparable relación de estos tres aspectos en toda su vida. En estricto sentido, de los tres, el primer sitio lo ocupa su trabajo intelectual. Un repaso echará luz al respecto.

Dentro su labor profesional hay que empezar diciendo que en 952 fue becario del Centro Mexicano de Escritores. En 953 fue jefe de prensa de la Secretaría de Educación Pública. Dos años más tarde ingresó al cine como argumentista, adaptador y supervisor de diálogos. En 1977 impartió un taller de cuento en la Facultad de Filosofía y Letras (Cadena, Agustín y Martínez, Miriam, 1999: 2).

Periodísticamente, fue cofundador de la revista Proceso. Fue colaborador de innumerables publicaciones, empezando en el medio impreso Suma Biográfica (1948), en la revista Estaciones ( 1956), en los suplementos México en la Cultura ( 1962) del semanario Siempre!, dirigido por Fernando Benítez, y en el periódico Ovaciones ( 1962) dirigido por Emmanuel Carballo; en 1967, en su revista El Cuento, Edmundo Valadés recopila algunos de sus relatos. Hacia 1970 comienza a publicar en el periódico Excélsior y en el suplemento Diorama de Cultura del mismo diario. A partir de 974 comienza una serie radiofónica, en las estaciones del Grupo IMER, Charlas de Garibay, que con varias interrupciones continúa a lo largo de su vida. Un año después da comienzo a una serie de programas en el canal por varios lustros: Autores y Libros; Poesía para militantes y Mujeres, mujeres, mujeres: comparte algunas emisiones con Germán Dehesa, Ikram Antaki, María Pía Lamberte y otros. 
En 1976 renuncia a Excélsior, en solidaridad con su director, Julio Scherer García; comienza entonces una larga colaboración en el semanario Pro- ceso. A partir de 983 comienza a publicar en El Gallo llustrado, suplemento del periódico El Día, que dirige Emmanuel Carballo. Y en 986 se hace colaborador del suplemento Revista Mexicana de Cultura, del periódico El Universal, dirigido por Eduardo Lizalde. Al año siguiente recibirá el Premio Nacional de Periodismo.

En cuanto a su obra periodística y su relación con los medios de comunicación, queda por agregar que a partir de 994 en el canal 22 del gobierno federal se transmiten viejos programas suyos en horarios nocturnos y sabatinos.

Pero Garibay también ha sido autor de numerosos guiones de cine y de más de 40 libros: La nueva amante (relatos, 949); Cuaderno de cuentos (cuentos, 950); Cuentos (tomo de cuentos, 952); Nuestra Señora Soledad en Coyoacán (crónica, 955); Mazamitla (novela, 954); El coronel (cuentos, 955); Beber un cáliz (novela 965, Premio Mazatlán de Litera- tura y Premio al Mejor Libro Extranjero Publicado en Francia en 976); Bellísima bahía (novela, 968); Lo que es del César (seis novelas cortas a partir de guiones, 970); Rapsodia para un escándalo (crónicas, diálogos y ensayo, 97 ); La casa que arde de noche (Premio al Mejor libro Extranjero Publicado en Francia, 975); Cómo se pasa la vida (cuentos, crónicas y ensayos a manera de diario, 1975); Diálogos mexicanos (en- sayo, 975); Lo que ve el que vive (crónica, 976); El gobierno del cuerpo (cuentos 977); Verde Maira (novela, 977); Las glorias del gran Púas (crónica-reportaje, 978); Mujeres en un acto (obra de teatro, 978); Acapulco (reportaje, 979); De lujo y hambre (reportaje, 98 ); Fiera infancia y otros años (libro de memorias, 982); Par de reyes (nove- la, 983); Aires de blues (cuento, 984); Confrontaciones (conferencias, 984);

El humito del tren y el humito dormido (cuento, 985); ;Lindas maestras! (teatro, 985); Garibay entre líneas (antología, 985); 
Chicoasén (reportaje, 986); Páginas sobre la Ciudad de México 1469-1987 (crónicas, 988); Tendajón mixto (ensayos y fantasías literarias, 989); Triste domingo (novela, 99 ); Cómo se gana la vida (memorias, 992); Paraderos literarios (experiencias literarias, 995); Vamos a la huerta del Toro Toronjil (relatos, 995); Treinta y cinco mujeres (retratos escritos, 996); Oficio de leer (reflexiones, 996); El joven aquel (relato, 997); Feria de letras (reflexiones, 998); y Lía y Lourdes (novela, 998).

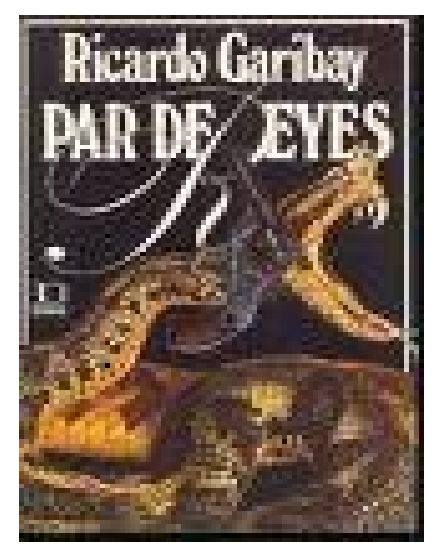

\section{Portada de Par de Reyes}

Sobre su trabajo literario, hace varios años dijo uno de los poetas y críticos literarios más prominentes de México, José Emilio Pacheco, que Beber un cáliz, sin duda la novela más importante de Ricardo Garibay, "significa para la prosa mexicana lo mismo que Algo sobre la muerte del mayor Sabines para nuestra poesía" (CADENA, Agustín y Martínez, Miriam Mabel, 999: 3- 4). Este libro, publicado en 965 y celebrado internacionalmente por su técnica innovadora, es el registro verbal de una larga agonía: la del padre del propio escritor. 
Se trata de un libro que pone de manifiesto lo que, de acuerdo con los escritores Agustín Cadena y Miriam Mabel Martínez, será la característica más notable de su expediente narrativo: la preeminencia de la propia vida como materia literaria; la autobiografía indirecta como único proyecto literario posible, asumido en múltiples rostros y con carácter de inevitable. De la tensión entre esta consigna y la búsqueda de los lenguajes que han de realizarla, continúan Cadena y Martínez, surgen los rasgos más per- durables del troquelado narrativo de Garibay: la aspereza viril de la voz, la contundencia de la representación directa, la nitidez del trazo argumental. "Todo esto se combina, se yuxtapone, se dinamiza para formar no sólo un estilo personal, sino toda una poética; es decir, un conjunto de procedimientos formales vertebrados en torno de una visión particular del mundo. Esta poética es el 'realismo iracundo', como lo ha definido Martha Robles" (Cadena, Agustín y Martínez, Mabel, 999: 6- 7).

Su aportación al medio de la filmografía nacional tiene alguna amplitud. Guiones suyos se utilizaron para películas de directores notables dentro de la cinematografía nacional y aun internacional.

De esta manera, Roberto Rodríguez filma La sonrisa de la virgen en

957, con argumento de Ricardo Garibay, y las actuaciones de María Gracia, Jorge Martínez de Hoyos y Prudencia Griffel (Carvajal, Rogelio, Ed., 2005: 294).

Un año más tarde, en 958, se filman tres argumentos de Ricardo Garibay: Ismael Rodríguez dirige Cuando jviva Villa! es la muerte, con Pedro Armendáriz y Elsa Aguirre; también dirige La cucaracha con María Félix, Dolores del Río, Emilio Fernández y Pedro Armendáriz; y Alejandro Galindo dirige La vida de Agustín Lara, con Germán Robles en el papel estelar. (Carvajal, Rogelio. Ed., 2005: 296) 
El largometraje Ladrón que roba a ladrón, de Jaime Salvador, se filmó en 959 con el guión de Ricardo Garibay, y la actuación de Luis Aguilar, Lorena Velásquez y Andrés Soler (Carlvajal, Rogelio, Ed., 2005: 297). En

960 se filma el argumento de Ricardo Garibay El siete copas. Dirigida por Roberto Gavaldón, la película cuenta con la actuación de Antonio Aguilar, Elvira Quintana, Julio Aldama y Pedro de Aguillón (Carvajal, Rogelio. Ed., 2005: 299). Al año siguiente se filman dos argumentos más de Ricardo Garibay: Los hermanos del Hierro, de Ismael Rodríguez, con Antonio Aguilar, Julio Alemán, Columbia Domínguez, Patricia Conde, Pedro Armendáriz; y Ánimas Trujado (El hombre importante) [en este caso la adaptación de la novela La mayordomía, de Rogelio Barrigas Rivas], de Ismael Rodríguez, con Toshiro Mifune, Antonio Aguilar, Columba Domínguez y Flor Silvestre (Carvajal, Rogelio, Ed., 2005: 300).

Pasaron dos décadas exactas antes de que una nueva película se basara en algún argumento suyo. En 98 , Roberto G. Rivera dirige El Milusos, con la actuación de Héctor Suárez. Es una de las películas más taquilleras en la historia del cine mexicano. Fue su última participación en la industrial del cine, y fue financieramente la más rentable (Calvajal, Rogelio, Ed., 2005: 3 $0)$.

Ahora bien: con base en su obra artística, intelectual y periodística, y también con base a las fuentes secundarias que insistentemente vinculan la obra de Garibay con su propia biografía, hay que insistir, se torna indispensable averiguar hasta qué grado es real esta afirmación hipotética.

Por ello se debe hacer mención de los episodios más notables en la vida privada del escritor. Se sabe muy poco de su 
infancia: de hecho, casi nada fuera de las cosas que narra desigualmente en su libro de memorias de la niñez, Fiera infancia y otros años. Indica que nació en Tulancingo, pero que su familia y él se vieron obligados a trasladarse a la Ciudad de México, por asunto de mera supervivencia. No sin dolor, recuerda que vivió precariamente, trabajando por las mañanas y estudiando en un colegio público en el turno vespertino. Pero esencialmente, en este libro señala la rudeza de sus años mozos, las anécdotas que vivió, sufrió, gozó, padeció, durante la primera etapa de su vida. Desde luego que también están narrados los episodios que jugaron un papel decisivo para que Garibay tomara por el camino de las letras.

Cuando tuvo que elegir el destino de su vida, se matricula en la Facultad de Derecho de la Universidad Nacional Autónoma de México. Pero re- conoce que faltaba constantemente a clases, por pasarse el tiempo en la cercana Facultad de Filosofía y Letras. Decide cambiarse de carrera, y entrar también a hacer estudios en El Colegio de México. De ambas instituciones, sin embargo, renunciaría más adelante. El entonces director de El Colegio de México, Alfonso Reyes, diría: "Otro es su camino, y pronto lo encontrará" 5 . Este sendero previsto por Alfonso Reyes es un renglón que hace falta investigar con suficiencia, a fin de conseguir el afianzamiento de la hipótesis de trabajo propuesta.

Hay otros aspectos de la vida personal de Ricardo Garibay en los que no se ha profundizado. Él mismo llegó a reconocer públicamente que prefería mantener en las sombras las cuestiones relativas a su vida per- sonal, tanto familiar como amistosa y amorosa. Lo que convierte a esta cuestión, naturalmente, en un filón que urge investigar.

Adicionalmente, el carácter explosivo de Garibay, relacionado con su admiración por el filósofo José Vasconcelos, es un tema, en apariencia al menos, estrechamente ligado a su vida privada. 
En todo caso, este vínculo que él mismo reconocía, debe indagarse en detalle mediante análisis estilísticos de literatura comparada.

El último punto a mencionar en lo que respecta a la hipótesis de trabajo, es el de su vida pública. En 968 conoce al presidente Gustavo Díaz Ordaz (Garibay, Ricardo, 983: 32). Con Luis Echeverría sostuvo una relación que se truncó, y que de acuerdo con el propio Garibay, lo hundió verdaderamente en la pobreza. La relación tanto con Díaz Ordaz como con Echeverría, y otros gobernadores y políticos de todo el país, es algo que debe indagarse y de lo que hasta el momento no existe noticia histórica de fiar. A efectos prácticos, cabe también la hipótesis sobre la importancia de estas relaciones, basándonos en las novelas de corte político que escribió, en las que denuncia corrupción, robo, pillaje, redes de mafias y una larga lista de vicios al interior de la política mexicana. Lo cierto es que para sostener esta hipótesis, hace falta indagar la relación entre la temporalidad de las novelas publicadas al respecto, con los hechos reales ocurridos en esos mismos años, así como la participación que en ellos pudo haber tenido, o no, Ricardo Garibay. Por otra parte, está su muy endémica amistad con los literatos de su tiempo. Baste decir que nunca trabó amistad con los escritores de prominente fama que tuvieron como guía infaltable a Octavio Paz.

En resumen, mi propuesta de hipótesis es la siguiente: partir de la posibilidad de un amplio vaso comunicante entre la obra intelectual, literaria y periodística de Ricardo Garibay, con las experiencias de su vida privada y con las relaciones públicas que tuvo con los políticos de México. A todo esto, hay que agregar algo que se acaba de mencionar: la evanescencia de sus amistades en los principales círculos literarios del país, vinculados a menudo con el pensamiento conservador. 
Y un agregado hipotético fundamental es la propuesta de división temporal para la biografía de Garibay en etapas. La primera pudiera abarcar desde su nacimiento hasta su adolescencia, a los 7 años en que elige convertirse en escritor; esto es, la etapa de formación que lo lleva a tomar conciencia de lo que quiere ser por el resto de sus días. Esta etapa coincide con sus años en la natal Tulancingo y terminan con su traslado a la vecindad de la Ciudad de México. A propósito, debe indagarse sobre su ascendencia paterna y materna. Hay que recordar que él mismo se refería constantemente en su obra periodística a Metztitlán, la tierra de su madre, y reconocía que nunca pudo superar el hondo desprecio que sentía hacia su padre. Esta etapa termina en la vecindad en la Ciudad de México. Es cuando estudiaba por las tardes y trabajaba por la mañana; empezaba sus escarceos amorosos con chicas de su edad y con mujeres mayores; ocurrieron sus primeros amoríos verdaderos; las vivencias que lo marcaron de por vida; los influjos de la época.

La segunda etapa empezaría desde la toma de conciencia del adolescente que elige el camino de las letras, hasta otro año definitorio: 955, cuando, dice Garibay mismo, "me empecé a sentir dueño de algunas líneas" (Venegas, Ricardo, 2005: 6). Durante esta etapa contrae nupcias y se convierte en hombre de familia, procrea cinco hijos, consigue distintos empleos, comienza con colaboraciones en medios impresos y escribe sus primeros guiones de cine y algunos libros. En Fiera infancia $y$ otros años hace constante referencia a esta franja temporal de su existencia; no sin dolorosa nostalgia, recuerda cuando sus guapas compañeras de clase sólo lo tomaban en consideración para que les hiciera las tareas, nunca lo tomaban en serio para ningún asunto, ni siquiera para invitarlo a alguna fiesta de amigos.

Pero por eso mismo, en la entrevista que le concede a Iris Limón señala que esa etapa estuvo definida por largas noches que pasaba en vela, leyendo vorazmente grandes cantidades de libros que tomaba prestados de la biblioteca escolar o que se allegaba con el dinero que podía ahorrar, privándose otros placeres materiales. También de sus libros se desprende que se trata de la etapa del descubrimiento.

Se introduce en el descubrimiento de las ciencias sociales y las humanidades, se matricula en la Facultad de Derecho de la UNAM, más tarde en la Facultad de Letras de la misma Universidad y por último en El Colegio de México, en donde cierto profesor le inculcará el cultivo de la poesía sacra; poesía que definirá sus preferencias literarias hasta el grado de convertirlo en un profundo conocedor de los poetas místicos, incluidos los autores de La Biblia, de los cuales preferirá absolutamente por en- cima de todos los demás, El Cantar de 
los Cantares. Igualmente trabará contacto con las que serán sus amistades profesionales y personales de mayor duración. Ahí está Froilán López, Rubén Bonifaz Nuño, María Luisa "La China" Mendoza, y otros menos conocidos. En esos mismos años consigue empleo y renuncia a la preparación universitaria. En adelante, la suya será una carrera de formación autodidacta, alejado en todo instante de las aulas académicas. Desde entonces y hasta 955, Garibay desempeña puestos periféricos en los medios de comunicación, en la literatura mexicana y en la industria del cine. De este modo, desempeña cargos públicos, empieza con colaboraciones en los medios de comunicación impresos, radiofónicos y televisivos citados arriba, y publica libros de cuentos o novelas muy pequeñas, en las que de acuerdo con la crítica, puso de manifiesto la contundencia de su virtud literaria más aplaudida: su "fino oído", que le permitía retratar el lenguaje popular en los diálogos de sus personajes.

Finalmente, su última etapa puede dar inicio una vez que se considera escritor, hasta el 3 de mayo de 999, día de su fallecimiento. Puede considerarse la etapa más intensa y rica en detalles de su biografía; corresponde a la época en que radica en su mítica casa de Cuernavaca, Morelos; para entonces es el escritor explosivo que más tarde se hará famoso; publica con periodicidad en varios medios impresos; aparece constantemente en radio y televisión; y otra cosa importante: cultiva sus relaciones con el círculo del poder mexicano, se expande como casanova y publica la parte más numerosa y rica de su prolífica obra.

Como en esta fase Garibay se convierte en el furibundo Garibay, escritor insolente que todos conocen públicamente, es también la fase en que, históricamente hablando, adquiere complejidad su biografía. Esta tercera y última etapa de su vida ofrece el mayor reto de cientificidad histórica. Es un periodo de la biografía de Garibay que demanda una escrupulosa investigación de información, a fin de hacer una inequívoca interpretación de la vida del escritor. Este hecho, sin embargo, ofrece la posibilidad de elaborar la biografía de Garibay con el rigor histórico que hasta el momento no existe en ningún sitio. 


\section{CONCLUSIONES}

En últimas fechas, Ricardo Garibay ha sido ampliamente reconocido por diferentes instituciones del medio hidalguense.

En el sexenio del gobernador hidalguense Manuel Ángel Núñez Soto, el Consejo Estatal para la Cultura y las Artes al alimón con el Fondo Estatal para la Cultura y las Artes, Conaculta y Editorial Océano, hizo imprimir en diez bellos tomos empastados en piel las Obras Reunidas de Ricardo Garibay. Ésa fue la primera muestra de la andanada de reconocimientos que pronto vendrían para el escritor de Tulancingo. La segunda fue la institución de un premio literario con su nombre. El gobierno de Miguel Ángel Osorio Chong creó el Premio Estatal de Cuento Ricardo Garibay, galardón que honra una de las facetas más logradas, que no más reconocidas del narrador hidalguense: sus cuentos. Con ello, el nombre de Garibay empieza a ser utilizado como vaso comunicante en- tre las letras mexicanas y la literatura naciente de la entidad. Un tercer reconocimiento fue la Biblioteca Central del Estado, inaugurada con el nombre precisamente de Ricardo Garibay. Abrió al público en mayo de 2007. Por último, el más reciente galardón es la medalla Miguel Hidalgo que el Congreso del Estado le concedió de manera post mortem. Ahora bien, en vista de los últimos reconocimientos que se han hecho al -de acuerdo con Agustín Cadena- primer escritor hidalguense de las letras modernas mexicanas y el narrador de Hidalgo más importante de todos los tiempos, resulta necesario obtener un documento que dé cuenta de manera amplia, integral, desapasionada, oportuna pero sobre todo ob- jetiva y rigurosa, de los hechos que componen la biografía de Ricardo Garibay.

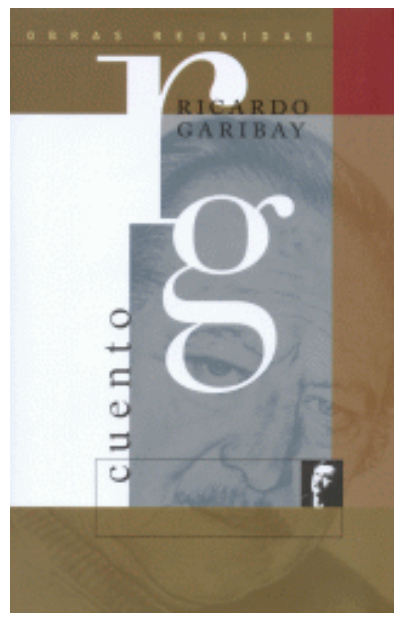


Adicionalmente, en mayo de 2009 se cumple la primera década de su acaecimiento. A decir de Carlos Monsiváis 6 , la vuelta de los años por fin traerá la reivindicación de Ricardo Garibay. De tal manera, Monsiváis barruntaba que en los institutos literarios, facultades de letras e instituciones culturales, se empezaría a prestar un interés inusitado a la obra de Garibay. La eventual biografía de Garibay está llamada a ser un texto de consulta obligada para los crecientes sectores literarios interesados en uno de los autores más originales y audaces de las letras mexicanas del siglo XX.

\section{NOTAS}

CORRALES VIVAR, Luis. "Garibay en la memoria", entrevista conmigo para la revista Vía libre, Pachuca, septiembre de 2005. pág. 33.

2 En 999, Alejandra Atala sostenía que siete años atrás a Garibay le habían diagnosticado cáncer de próstata. Esto es, en 993.

3 En la biblioteca Samuel Ramos de la Facultad de Filosofía y Letras de la Universidad Nacional Autónoma de México, existen tres tesis sobre diferentes obras de Garibay. Y actualmente se elaboran dos más: una sobre la novela Beber un Cáliz y otra sobre Par de reyes. Ambos proyectos de análisis están enfocados a la polifonía y el dialogismo presentes en las dos obras literarias.

4 El cuento Morir de Amor se publica en el número octubre-noviembre de 995 de la revista Tierra Adentro. Es un error datarlo con fecha de 996, como está en las Obras reunidas de Ricardo Garibay. 0 volúmenes. Coed. Editorial Océano, Consejo Estatal para la Cultura y las Artes de Hidalgo y Consejo Nacional para la Cultura y las Artes. México, 200 -2005.

5 Díaz Arciniega, Víctor. "Diplomacia condiscreto acento", en http://cvc.cer- vantes.es/literatura/escritores/a_reyes/entorno/diaz.htm

6 Monsiváis, Carlos. "De la hora del ángelus a la del zapping. La crónica en

América latina" en Letras libres, diciembre de 2005, Año VII, Núm. 84. pág. 50. 


\section{FUENTES DE CONSULTA}

- ACEVES, Rocío y Arce, Socorro ( 999), La conquista de la palabra, entrevista con Ricardo Garibay, México: Universidad de Colima, Col. Voz de Tinta.

- ATALA, Alejandra (2003), Señor mío y Dios mío. Ricardo Garibay: la fiera inteligente, México: Océano.

- CADENA, Agustín y Martínez, Miriam Mabel ( 999), Diáspora. Hidalgo: una narrativa en exilio, Hidalgo: Gobierno del Estado de Hidalgo, Siste- ma de Educación Pública de Hidalgo, Consejo Estatal para la Cultura y las Artes. Colección Orígenes.

- CORRALES, Luis y Garibay, Ricardo, Diálogos hidalguenses. Pachuca:

Universidad Científica Latinoamericana de Hidalgo.

- ECO, Umberto ( 997), Cómo se hace una tesis, Barcelona: Gedisa.

- GARIBAY, Ricardo (200 ), Obras Reunidas, T. II, México: Coed. Editorial Océano, Consejo Estatal para la Cultura y las Artes de Hidalgo, Fondo Estatal para la Cultura y las Artes de Hidalgo, Consejo Nacional para la Cultura y las Artes. México.

_, Fiera infancia y otros años ( 982), México: Joaquín Mortiz.

-, Tomo Ocho. Varia en Obras Completas (200 ) México: Coed. Edi- torial Océano, Consejo Estatal para la Cultura y las Artes de Hidalgo, Fondo Estatal para la Cultura y las Artes de Hidalgo, Consejo Nacional para la Cultura y las Artes.

, Tomo Nueve. Teatro y Cine en Obras Completas (2000). México: Coed. Editorial Océano, Consejo Estatal para la Cultura y las Artes de Hidalgo, Fondo Estatal para la Cultura y las Artes de Hidalgo, Consejo Nacional para la Cultura y las Artes.

- LIMÓN, Iris. Signos vitales de Ricardo Garibay (2000), México: Colibrí.

- VENEGAS, Ricardo, Memoria, espíritu y astucia en la obra de Ricardo Garibay. Inédito.

- VENEGAS, Ricardo y Garibay, Ricardo, Escribir para seguir viviendo: entrevistas con Ricardo Garibay (2000), Cuernava- ca, Morelos: Instituto de Cultura de Morelos. Cuernavaca. 